\title{
LAS CONFERENCIAS DOMINICALES EN LA ASOCIACIÓN PARA LA ENSEÑANZA DE LA MUJER: DOS PARADIGMAS HUMANOS
}

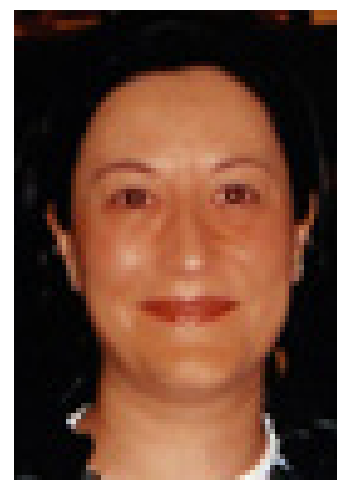

\section{Juana García Romero}

Universidad Autónoma de Madrid, España

juanagarciaromero.1969@gmail.com

\section{RESUMEN}

En este ensayo se exponen algunos de los pasos fundamentales de la enseñanza de la mujer a partir del decreto de 1868, que permite fundar libremente centros de enseñanza. En 1869, surgen como actividad formativa una serie de conferencias dominicales en las que aparecen dos propuestas educativas que dan lugar a dos tipos de mujer, cuyo fin común es facilitar el paso a la sociedad moderna que ya existía en otros países europeos, y que empezaba a darse, paulatinamente, en España. En 1870 se funda la Asociación para la Enseñanza de la Mujer para consolidar el ideal de mujer que propone Fernando de Castro.

Palabras clave: Conferencias dominicales, enseñanza, mujer

\section{DOMINICAN CONFERENCES IN THE ASSOCIATION FOR THE TEACHING OF WOMEN:}

TWO HUMAN PARADIGMS

\begin{abstract}
The article focuses its content on some fundamental steps of women's education introduced by the Education Act 1868, which allowed free foundation schools. In 1869, some series of Sunday lectures were introduced as training activities. So, two different educational projects emerged, which would lead two different types of women; proposals, whose common aim was to help the gradual transition to a more modern society, similar to the one already present in other European
\end{abstract}


Las conferencias dominicales en la asociación para la enseñanza de la mujer: Dos paradigmas humanos Juana García Romero (39:46)

countries. In 1870, the Association for Women's Education was founded with the purpose of strengthening Fernando de Castro's ideal women.

Key words: Sunday conferences, teaching, woman.

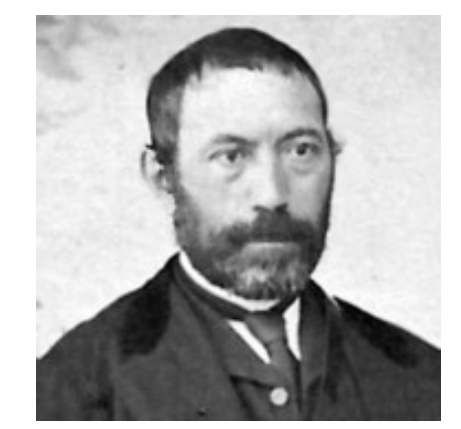

Fernando de Castro Pajares

(1814-1874)

\section{INTRODUCCIÓN}

En el decreto de 21 de octubre de 1868 se lee que «la enseñanza es libre en todos sus grados y cualquiera que sea su clase [y que] todos los españoles están autorizados para fundar establecimientos de enseñanza» (Labra, 1888, p. 35).

Debido a esto, don Fernando de Castro (1868) reclama, pública-mente, lo siguiente «fomentar la creación de asociaciones que funden la enseñanza en las clases obreras, y la propaguen hasta en las más retiradas aldeas; abrir cursos especiales destinados á completar la educación de la mujer; procurar que la juventud se agrupe en academias científicas, y hacer de modo que nuestras bibliotecas y museos puedan utilizarse libremente [...], para mejorar el estado intelectual y moral de nuestro pueblo: mejora sin la que, creedme, la libertad perece, y se apaga en la indiferencia el amor á la patria y á las instituciones» (p. 13). Solicita, para ello, la colaboración del profesorado español.

Así pues, la Asociación para la Enseñanza de la Mujer es la institución que funda Fernando de Castro, en 1870, para llevar a cabo su proyecto educativo donde se reconoce la importancia de la mujer en el progreso de la sociedad, siendo el ideal católico-cristiano el que se consolida para la posteridad. 
Recordar que Fernando de Castro (1814-1874) fue contemporáneo de Julián Sanz del Río (1814-1869), y cultiva su pensamiento en la filosofía cristiana.

Las conferencias dominicales «se dieron desde el 21 de Febrero al 23 de Abril de 1867, en el Paraninfo viejo de la Universidad Central» (Labra, 1888, p. 39), y dan forma a dicho proyecto desde 1869, donde el krausismo español está presente y cuyo objetivo, a corto plazo, se centra en reducir el alto analfabetismo en que se encuentra la España del siglo XIX, por ser un problema que atañe a todas las clases sociales, y así lo expresa Fernando de Castro cuando hace suyas las palabras de don Miguel de Cervantes Saavedra: «Y no penséis Señor, que yo llamo aquí solamente vulgo á la gente plebeya y humilde; que todo aquel que no sabe, aunque sea señor y príncipe, puede y debe entrar en número de vulgo» (Castro, 1869a, p. 11).

Analizando las conferencias aparecen dos propuestas educativas que dan lugar a dos tipos de mujer, cuyo fin común es facilitar el paso a la sociedad moderna que ya existía en otros países europeos, y que empezaba a darse, paulatinamente, en España.

Rafael María de Labra (1869) muestra cómo la legislación beneficia a la mujer soltera, al concederle casi los mismos derechos que al hombre (p. 22), pero una vez contrae matrimonio su situación cambia jurídica y socialmente, y así lo específica cuando dice «la mujer soltera es digna, respetable sin duda; pero la esposa y la madre es augusta» (p. 24) donde «la madre castellana no tiene autoridad propia sobre sus hijos» (p. 27).

Sin embargo, en ambas propuestas educativas se reconoce que el matrimonio como institución es «la única unión que guarda el debido respeto á la dignidad de los dos sexos» (Álvarez-Ossorio, 1869, p. 8) pues es el lugar donde se lleva a cabo esa «armonía de oposición, en la igualdad de dos desigualdades [gracias a] la simpatía, que es la base, que es la magnífica portadora del amor» (p. 11), y es a través del Derecho y las instituciones pertinentes desde donde se regula la vida en las sociedades humanas, considerando el matrimonio civil como una institución más, sin excluir al religioso (Rodríguez, 1869, p. 22).

Para Fernando de Castro (1869b), el cristianismo es la doctrina que garantiza la unidad humana porque integra al hombre y a la mujer, cuya personalidad racional parte del mismo origen, es decir, de su semejanza con Dios (p. 4); sin embargo, el destino que dispone la Providencia para la mujer es la de esposa y madre, quedando así limitada su capacidad de actuación al ámbito doméstico y familiar.

En la misma línea se encuentra Pi y Margall (1869) pues sigue reservando el ámbito privado para la mujer. Afirma que la misión a cumplir por aquélla es la educación de sus hijos (p. 10), y sólo considerando la humanidad en su conjunto y estudiándola a través de las relaciones existentes, 
Las conferencias dominicales en la asociación para la enseñanza de la mujer: Dos paradigmas humanos Juana García Romero (39:46)

entre las generaciones pasadas y las presentes, serán capaces de trabajar por las venideras (p. 14).

El destino a desempeñar en la Humanidad y la misión a cumplir en la Sociedad, bajo un mismo sentimiento religioso, marcan las pautas de la educación a seguir por la mujer.

Se distinguen dos líneas de actuación: una, de tendencia conservadora, representada por Fernando de Castro, Joaquín María Sanromá, Juan de Dios de la Rada y Delgado, Francisco de Paula Canalejas, Fernando Corradi, Antonio María Segovia, Francisco Asenjo Barbieri, Tomás Tapia y Antonio María García Blanco, y otra, de tendencia liberal, representada por Rafael María de Labra, Santiago Casas, Segismundo Moret y Prendergast, José Echegaray, Gabriel Rodríguez, Florencio Álvarez-Ossorio, José Moreno Nieto y Francisco Pi y Margall.

Para los conservadores, la mujer tiene que recibir una educación de tipo tradicional, pues se trata de formar su carácter. Si antes fue educada en las labores domésticas, ahora es en las labores elegantes y finas llamadas por Joaquín María Sanromá (1869) educación de buen tono (saludo, baile, piano, lenguas extranjeras) porque el prestigio social dependía, en buena medida, de su comportamiento como manifestación del ser sensible e inteligible que es y, por ello, se la invita a participar en la ciencia moderna (p. 22), centrada en ejercitar su memoria histórica para tomar conciencia de su situación actual (Rada, 1869, p. 6), y cumplir con el ideal de mujer modesta que la Providencia le encomendó seguir, siendo la responsable de mantener el amor como guía de la educación de sus semejantes (Corradi, 1869, p. 18); por tanto, su formación se basa en el estudio de la Historia, la Literatura y la Religión, principalmente.

Para los liberales, la razón humana es única y así lo manifiesta José Echegaray (1869) cuando dice «la mujer, como el hombre, discurre, piensa, juzga, compara, analiza, sintetiza; ejerce, en fin, las múltiples y varias funciones de la razón humana. Luego todo lo que se refiere á la razón puede y debe ser comprendido por la mujer; luego no hay ciencia que sea, ni pueda ser, radical y terminantemente ajena al pensamiento femenino» (p. 7).

Consideran que las facultades del ser humano están limitadas por su condición individual, donde la educación tiene que procurar la armonía o equilibrio entre ellas, resultando ser el gran problema a resolver porque de ello depende la vocación y la profesión del hombre (Moret, 1869, p. 9).

Esto trae consigo otro enfoque, a la hora de estimar qué tipo de educación debía recibir la mujer. Surge, entonces, una educación más moderna.

Segismundo Moret propone que la mujer, como madre y responsable de la preparación a la educación de sus hijos (p. 11), tiene que adquirir ciertos conocimientos que, hasta ahora, no habían sido considerados. 
Esta propuesta educativa recomienda la participación de la mujer en la Ciencia porque la comprensión de la misma, no se debe a la falta de inteligencia de aquélla, sino al maestro, por no hacerse entender (Echegaray, 1869, p. 12). Se le considera un ser racional y, como tal, puede acceder al conocimiento científico a través del estudio de las Ciencias Físicas, las Ciencias Económicas y Sociales para conseguir su bienestar en la vida, conforme a su naturaleza humana, respetando su libertad individual. La actividad humana queda condicionada por el interés personal que tendrá que ser regulada a través de la ley, donde la Justicia será la encargada de organizar la Sociedad (Rodríguez, 1869, p. 18).

Los dos tipos de mujer que resultan de estas propuestas educativas reciben conocimientos distintos acerca de una misma realidad:

Mujer conservadora: estudia la tradición sin ánimo de cambio, sin cuestionarla; le interesa las manifestaciones artísticas y religiosas como prueba de verdad por ser la expresión más inmediata del interior y la imaginación humana al potenciar la creatividad espontánea; prima el sentimiento humano ante la razón.

Mujer liberal: estudia para cambiar y mejorar lo transmitido racional-mente porque, desde ahí, se asegura el progreso científico en beneficio de los seres vivos y la modernización de la sociedad; el hecho concreto es su prueba de verdad por ser el reflejo más real del proceso lógico de toda existencia, capaz de dar coherencia al llamado avance histórico de la humanidad; prima la razón ante el sentimiento humano.

No obstante, ambos tipos de mujer tienen un nexo común que las enaltece ante los demás y es su afán de superación personal; esto supuso, a su vez, que la decisión de la mujer fuera considerada una expresión más de la condición humana.

Estas definiciones, también, se pueden aplicar al hombre porque ambos son individuos que se desarrollan en la sociedad humana, por tanto, se puede hablar de dos paradigmas humanos: persona conservadora y persona liberal.

\section{Conclusión}

En ambas propuestas educativas se estima que la mujer se interese por la Ciencia pero, a su vez, se la excluye de la misma, y así lo específica Fernando de Castro (1869b) cuando dice «no aprendáis tanto por cultivar en sí misma la Ciencia y para profesarla en la Sociedad, cuanto para aplicarla en el círculo íntimo de la familia y contribuir poderosamente á despertar la vocación de vuestros hijos, [y para las que no adquieran estos compromisos propone que se las facilite el camino de ciertas profesiones, y] os dignifiquéis no menos que ésta ante la Sociedad, [por tanto], se trata, no de que unas cuantas mujeres de clase alcancen mucho, sino de que todas sepan lo suficiente 
Las conferencias dominicales en la asociación para la enseñanza de la mujer: Dos paradigmas humanos Juana García Romero (39:46)

para vivir como miembros dignos de la Sociedad [sin olvidar] que debe educarse, ante todo, para ser esposa y madre, y que la Providencia la ha colocado al lado del hombre en las tres edades que recorre la vida: en la infancia, para guiar los primeros pasos del niño; en la virilidad, para moderar las pasiones del hombre; y en la vejez, para mantener el vacilante paso del anciano» (p. 13).

Así pues, la mujer continua a la sombra del hombre y, además, Fernando de Castro parece olvidar que, también, en ella se dan esas tres edades que recorre la vida (infancia, feminidad y vejez); todavía es más rotundo cuando afirma «vuestro destino, como esposas y como madres, es aconsejar, influir; de ninguna manera imperar» (p. 16).

Todo esto es lo que frena el desarrollo real de la mujer pues, por un lado, limitan su capacidad desde niña, para tomar conciencia por sí misma de su propia dignidad como ser humano racional, al quedar sometida a la del hombre, y así lo expresa Fernando Corradi (1869): «la dignidad del hombre es un patrimonio de la mujer. Toda medida, de cualquier género que sea, política, económica ó social, que ofenda al primero, le humille ó empobrezca; condena la segunda, al llanto, á la vergüenza ó á la miseria» (p. 21) y, por otro, se la excluye de la participación en las especulaciones racionales y filosóficas, al igual que del ámbito político (Moreno, 1869, p. 14), pues sólo puede ejercer su influencia a través del marido como así queda, también, recogido en la conferencia de José Moreno Nieto.

Sin embargo, es su trabajo el medio que asegura su dignidad como persona autónoma y útil, al ser un individuo libre que se desarrolla en Sociedad, y esto no queda garantizado con el proyecto educativo premoderno de Fernando de Castro, porque está enfocado a suavizar la difícil situación en la que se encuentra la mujer de dicha época, pero sin excesivos cambios, por ir dirigido a mujeres de sólida reputación y clase social acomodada, cuya actividad se centra en ser esposas y madres de familia.

En estos momentos, al maestro se le considera pieza clave para la modernización de la sociedad española y aunque, según consta en la Real Cédula de 14 de Agosto de 1768 (que es la ley 9, título I, lib. VIII de la Novísima Recopilación), la educación de las niñas estaba a cargo de la Iglesia, sin embargo, se «manda que en los pueblos principales se establezcan otras casas, con matronas honestas é instruidas, que cuiden de la educación de las niñas, instruyéndolas en los principios y obligaciones de la vida civil y cristiana, y enseñándolas las habilidades propias de su sexo, entendiéndose preferentes las hijas de labradores y artesanos, porque á las otras podían proporcionárseles enseñanza á expensas de sus padres, y aún pagar y buscar maestras [siendo, en 1771, cuando a la maestra se la obliga a realizar] un examen de doctrina ante la persona que diputase el ordinario y la licencia de la justicia» (Labra, 1888, p. 49) porque «el legislador se preocupó tan solo de que la enseñanza 'fuera uniforme', y de que las maestras tuvieran buenas costumbres y supiesen la doctrina cristiana, coser y leer» (p. 50); no obstante, es a partir de 1855 
cuando se inicia el proceso de feminización docente en España (San Román, 2006, p. 214), al que contribuirá este proyecto educativo.

Se puede afirmar que Fernando de Castro sigue las directrices marcadas por la filosofía mística importada de Alemania, por Julián Sanz del Río (Araquistáin, 1962, p. 21); se le puede llamar hombre premodernista pues, según Jobit, «el krausismo español fue una especie de premodernismo» (p. 37) porque no se preocupa «por el gran problema de España: por la reforma de nuestra economía, por la revolución industrial y agrícola del país, [sino que se centra en] la reforma del hombre y de las instituciones políticas y sociales» (p. 39), concretamente, en la reforma basada en la Constitución de 1869, en la reforma de la Iglesia española (Chacón, 2006, p. 157) y en «la interrelación entre krausismo, fröbelismo y promoción de la mujer, característica del krausismo alemán» (Menéndez, 1999, p. 35) y, por ello, la Asociación se crea en Madrid para llevar a cabo dicho ideal de mujer, siguiendo las pautas de lo que Enrique Ureña denomina krauso-fröbelismo (p. 31); así pues, Fernando de Castro confía en la educación individual ante la instrucción colectiva para asegurar la dignidad personal.

En el siglo XIX, la Pedagogía es la gran protagonista, por ser la ciencia que garantiza el orden establecido y evita la revolución política y social, pues así lo refleja la historia de este país. La educación será la responsable del progreso y la renovación estética de la sociedad española; pero esto, en el caso de la mujer fue sólo un intento, así pues, la igualdad es la gran utopía a conseguir por el ser humano.

\section{Referencias bibliográficas}

Álvarez-Ossorio, F. (1869). Algunas consideraciones generales sobre el matrimonio. Madrid: [s. n.] (Imprenta y estereotipia M. Rivadeneyra).

Araquistáin Quevedo, L. (1962). El pensamiento español contem-poráneo. Buenos Aires, Losada.

Castro, F. de (1868). Discurso que en la apertura de los estudios de la Universidad Central, en la toma de posesión del Doctor Don Fernando de Castro, Catedrático de la Facultad de Filosofía y Letras, nombrado Rector de la misma, y en la reposición de los Catedráticos separados, leyó el nuevo Rector el 1. ${ }^{\circ}$ de noviembre de 1868. Madrid: [s. n.] (Imprenta de José M. Ducazcal).

(1869a). Discurso. Fiesta literaria celebrada en honor de Miguel de Cervantes Saavedra, pp. 9-16. Madrid: [s. n.] (Imprenta de Gabriel Alhambra). 
Las conferencias dominicales en la asociación para la enseñanza de la mujer: Dos paradigmas humanos Juana García Romero (39:46)

(1869b). Discurso inaugural. $2^{\mathrm{a}}$ ed. Madrid: [s. n.] (Imprenta y estereotipia M. Rivadeneyra). Chacón Godás, R. (2006). Don Fernando de Castro y el problema del catolicismo liberal español. Madrid: Fundación Fernando de Castro/Fundación Diego de Sagredo.

Corradi, F. (1869). De la influencia del cristianismo sobre la mujer, la familia y la sociedad. Madrid: [s. n.] (Imprenta y estereotipia M. Rivadeneyra).

Echegaray, J. (1869). Influencia del estudio de las ciencias físicas en la educación de la mujer. Madrid: [s. n.] (Imprenta y estereotipia M. Rivadeneyra).

Labra, R. M. de (1869). Sobre la mujer y la legislación castellana. Madrid: [s. n.] (Imprenta y estereotipia M. Rivadeneyra).

(1888). D. Fernando de Castro. Estudio biográfico. Madrid: [s. n.] (Establecimiento tipográfico de El Correo, á cargo de F. Fernández).

Menéndez Ureña, E. (1999). La actualidad del krausismo en su contexto europeo. Madrid: Parteluz.

Moreno Nieto, J. (1869). Influencia de la mujer en la sociedad. Madrid: [s. n.] (Imprenta y estereotipia M. Rivadeneyra).

Moret y Prendergast, S. (1869). Influencia de la madre sobre la vocación y profesión de los hijos. Madrid: [s. n.] (Imprenta y estereotipia M. Rivadeneyra).

Pi y Margall, F. (1869). Sobre la misión de la mujer en la sociedad. Madrid: [s. n.] (Imprenta y estereotipia M. Rivadeneyra).

Rada y Delgado, J. de D. de la (1869). Sobre la educación de la mujer por la historia de otras mujeres. Madrid: [s. n.] (Imprenta y estereotipia M. Rivadeneyra).

Rodríguez, G. (1869). Influencia de las ciencias económicas y sociales en la educación de la mujer. Madrid: [s. n.] (Imprenta y estereotipia M. Rivadeneyra).

Sanromá, J. M. (1869). Sobre la educación social de la mujer. Madrid: [s. n.] (Imprenta y estereotipia M. Rivadeneyra).

San Román Gago, S. (2006). Las primeras maestras: los orígenes del proceso de feminización docente en España, $2^{\mathrm{a}}$ ed. Barcelona: Ariel. 